\title{
The use of Advanced Numerical Models to support the Design of Coastal Structures
}

\author{
Dr Ida Brøker \\ DHI Water \& Environment \\ Agern Allé 5, DK-2970 Hørsholm, Denmark
}

\begin{abstract}
Since the late eighties a huge effort has been put into the development of coastal morphological models. The morphological models have now reached a stage where they are useful tools in the process of design of ports, harbours, beach parks and other structures in the coastal zone. The paper will illustrate the present stateof-the-art through a number of practical examples. These examples will concentrate on the optimisation of harbour layouts on sandy beaches with regard to natural by-pass and minimisation of sedimentation. The use of the computational fluid dynamics technique to study details around harbour entrances will be presented and the potential of this technique will be discussed. Furthermore, examples of successful beach restoration projects will be presented. The key to success for these projects has been to develop schemes, which utilise the natural possibilities on the specific site. The quantification of coastal processes and the subsequent testing of the schemes have been done by advanced numerical modelling tools. Research and further development and refinements are still required to fill in gaps in the understanding and quantification of coastal processes. Trends seen from the view point of practical applications in the further research and developments will be discussed.
\end{abstract}

\section{Brief Introduction to Numerical Modelling Tools}

Over the past decades, numerical models have increasingly become support tools to shoreline management and design of coastal structures. The tools comprise:

- Littoral drift and shoreline evolution models suited for relatively uniform sandy beaches, which, given proper input on variability of the wave conditions along the shore and with time, cast light over the large-scale shoreline developments.

- 2-dimensional (in plan) wave and hydrodynamic models for the detailed study of waves and flow fields on complex bathymetries and in the vicinity of coastal structures.

- Quasi 3-dimensional models for sediment transport.

- Coastal area morphological modelling tools to appraise the short- to mediumterm morphological response of the coast to for example coastal structures, harbours, shore-face nourishments etc.

- Models for the direct simulation of processes close to structures responsible 
for local scour, sedimentation in harbour entrances etc.

The littoral drift and shoreline evolution model typically includes wave transformation, longshore wave driven currents, longshore and cross-shore sediment transport, shoreline evolution and coastal profile evolution. The bed contours are assumed to be parallel and quasi-uniform in the longshore direction and the waves and currents are considered to be quasi-stationary. These two basic assumptions limit the use of the tool to cases of long and uniform sandy beaches and cases where the shoreline evolution is the result of the overall gradients in the longshore sediment transport capacity. On the other hand, due to these assumptions, long coastal stretches can be covered over long time spans and the complex is a fast tool for calculation of equilibrium orientations of coast lines. See for instance Fredsøe and Deigaard (1992).

The two dimensional so-called area models consist of a series of modules capable of simulating different wave-related, current and sediment transport processes. The following modules are currently most used for coastal morphological studies:

Wave models: still the very advanced wave models which include all important processes in the coastal zone are not fast enough to be applied in practical cases where many different wave conditions have to be considered. Very efficient wind wave models are, however, available and are excellent tools when diffraction is not a dominant process, Holthuijsen et al. (1989). Wave models based on the parabolic approximation to the mild-slope equation, Kirby (1986) have proven to be useful for smaller areas in the order of magnitude 10 by $10 \mathrm{~km}$. Both models account for the effects of shoaling, refraction, breaking, directional spreading and bed friction. The mild slope models further include partial diffraction and forward scattering, whereas the wind wave models include growth and decay of shortperiod waves and the effects of current may be included. In both types, the dissipation of wave energy due to breaking is parameterised. A much used approach is the model of Battjes and Janssen (1978).

The hydrodynamic model calculates the flow field from the solution of the depth-integrated continuity and momentum equations, Abbott (1979). In addition to wind and tide, the forcing terms may include the gradients in the radiation stress field as calculated by the wave module of the morphological modelling system. The currents and the mean water level are calculated on a bed evolving at a constant rate equal to $\partial z / \partial t$ as calculated by the sediment transport module.

The non-cohesive sediment transport model is used to calculate the transport rates of graded sediment and the rates of bed level change $\partial z / \partial t$ under the combined action of waves and current. The transport model for sand is an intrawave period sediment transport model which calculates the total (bed load + suspended load) transport rates of non-cohesive sediment. The model accounts for the effects of waves propagating at an arbitrary angle to the current, breaking/unbroken waves, uniform/graded bed sediment, plane/ripple covered bed when calculating the local rates of total load transport, see e.g. Fredsøe (1984) and 
Deigaard et al. (1986). The model includes a quasi-3-dimensional description of the flow and the sediment transport, as described in Elfrink et al. (2000). Use of this approach allows calculation of net sediment transport rates both in the longshore and cross-shore directions.

Morphological modelling complex. The three above-mentioned models, waves, hydrodynamics and sediment transport are combined into a morphological modelling system, see Johnson et al (1994) and Johnson and Zyserman (2002).

The refined flow model in three dimensions with free surface solves the NavierStokes equations and uses the so-called volume of fluid method to describe the water surface, see Mayer et al (1998), Christensen et al (2005). This type of model is becoming a useful tool for calculation of forces on structures, run-up and overtopping, and in the years to come more applications such as sedimentation in harbour entrances and scour around structures will become feasible.

In the present paper, examples of the application of some of the above-mentioned modelling tools are presented.

\section{Optimisation of Harbour Layouts, two Danish Cases (Thorsminde and Hanstholm)}

The West Coast of Denmark is exposed to the severe North Sea wave climate. The west coast, from the Wadden Sea in the south to the Skaw in the north, is several hundred kilometres long. The net sediment transport along the coastline ranges from 500,000 to $1,000,000 \mathrm{~m}^{3} /$ year. Natural shoreline retreats of up to $5-8$ $\mathrm{m} /$ year take place at some stretches. The sandy coastline is undergoing constant reshaping mainly due to gradients in the longshore sediment transport. This coastal landscape was basically formed following the latest glacial period. An equilibrium shape has not been reached and even though till cliffs, forming semihard points, are present, the entire coastline is slowly retreating in its natural condition.

Thorsminde fishery port is located at a tidal inlet on this coastline, on one of the narrow barriers dividing the coastal lagoons from the sea. The port is located at the entrance to the coastal lagoon. Sluices regulate the water exchange between the lagoon and the sea. Figure 1 shows a location map and a close-up of Thorsminde. Hanstholm is located $100 \mathrm{~km}$ further to the north at a natural semihard point where the coastline turns about $45^{\circ}$ clockwise.

Thorsminde Port is located in the central part of this very exposed stretch, where the net littoral drift is southward with an order of magnitude of 0.4 million $\mathrm{m}^{3} /$ year, but where the gross transport is several times larger. The sedimentation and shoaling problems prior to the optimisation affecting the harbour entrance are illustrated in Figure 2. The left and right panels show the results of the simulation of nearshore waves and wave-driven currents for north-westerly 
waves and south-westerly waves, respectively. The simulations were performed using a spectral wind wave model and a depth-integrated hydrodynamic model. For north-westerly waves, it is clearly seen how the wave-driven currents converge at the end of the northernmost groyne and diverge south of the inlet jetty. The southward sediment transported along the coast will thus be pushed around the tip of the groyne and will settle in the large eddy south of the inlet jetty. For south-westerly waves, the northward littoral transport will be pushed directly into the harbour entrance.
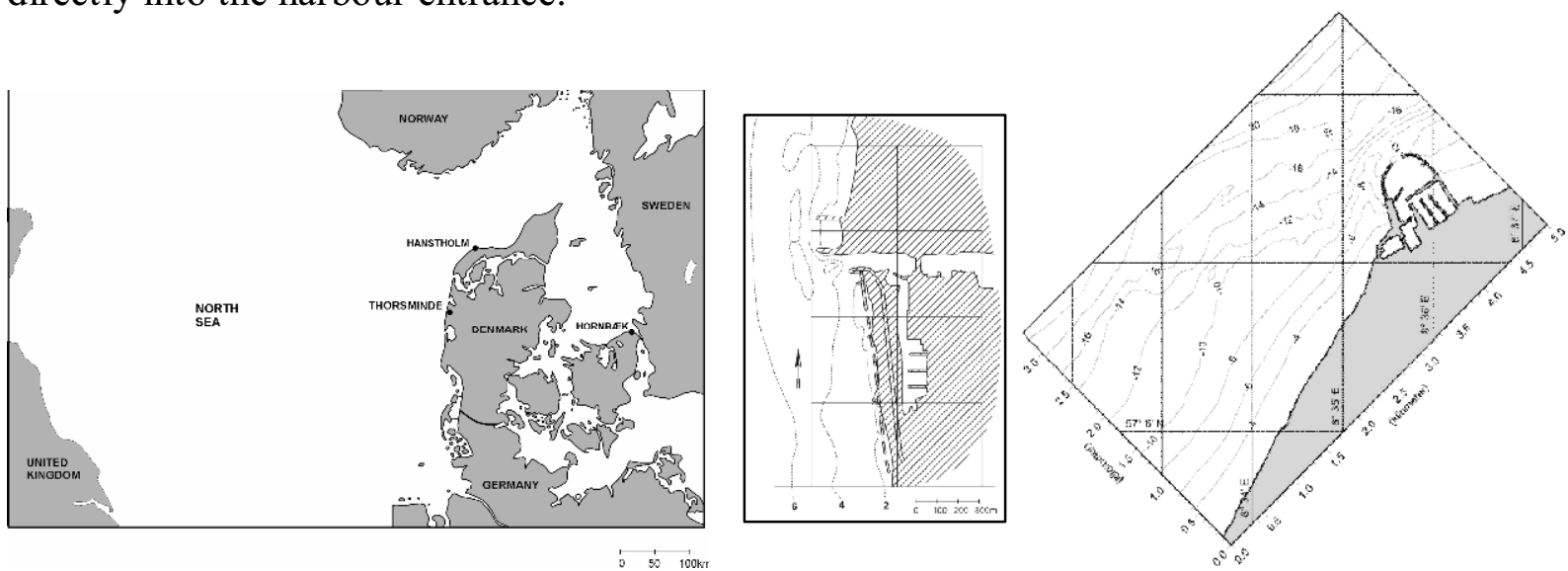

Figure 1: Location map and close-up of Thorsminde Port before optimisation and Hanstholm.
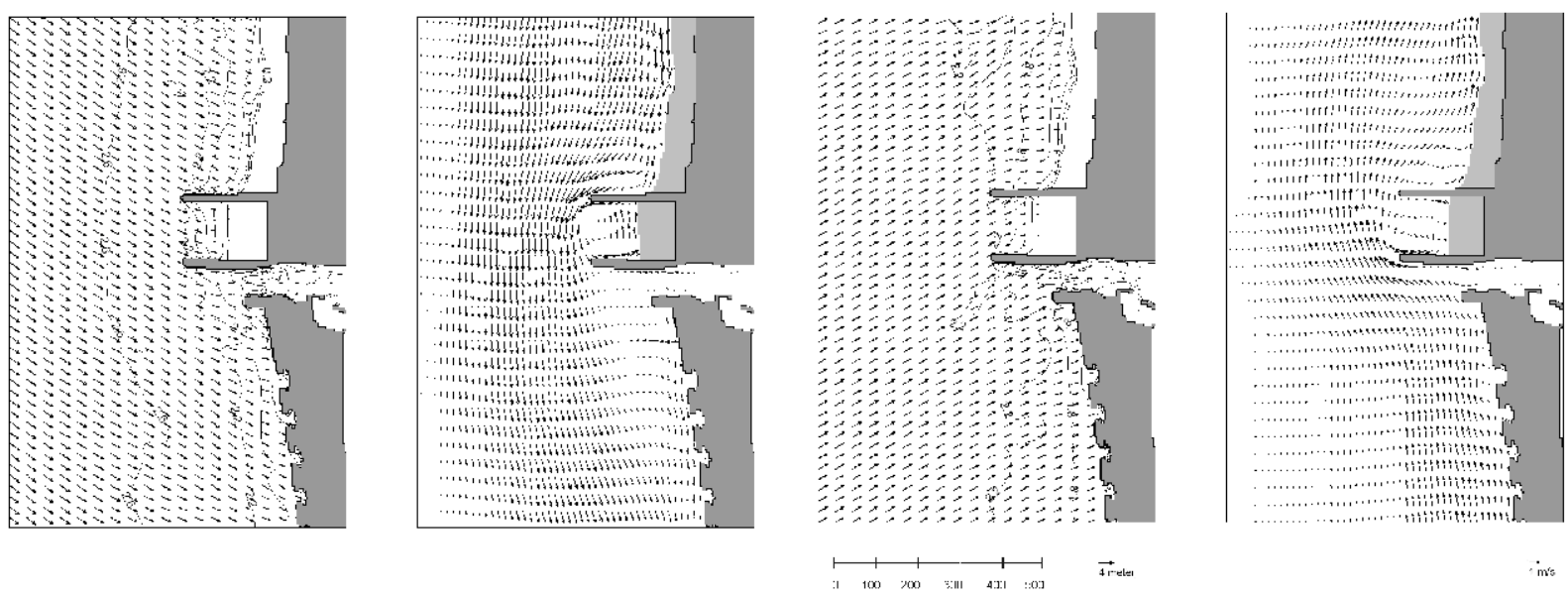

Figure 2: Examples of wave and flow fields around the existing harbour. Left two panels: Hs = $3.0 \mathrm{~m}, 315^{\circ}$. Right two panels: $\mathrm{Hs}=2.5 \mathrm{~m}, 235^{\circ}$.

The natural (equilibrium) water depth at the entrance to the harbour is $2-3 \mathrm{~m}$, if no maintenance dredging is carried out. The harbour entrance is at present dredged to 3.5-4 m. The harbour is "small" compared to the width of the littoral zone and there is a need for maintenance dredging after almost every storm, partly due to sedimentation in the entrance channel and partly due to shoaling in front of the entrance area. On average, 0.10 million $\mathrm{m}^{3}$ are dredged every year. The downdrift coastline suffers from erosion due to the partial blockage of the littoral drift by the harbour. The southern beach is protected by beach breakwaters and some of the 
dredged material is placed artificially on the eroding beach.

The goal of a new harbour layout can be summarised as follows:

- To increase the natural depth in front of the entrance, thereby decreasing the downtime for access to the port and decreasing maintenance dredging.

- To improve navigation conditions to the port, especially during storms from $\mathrm{SW}$, where opposing waves and currents co-exist in the present layout.

It may be a positive side effect of a new layout that the downdrift erosion is reduced.

A new layout has been developed for Thorsminde harbour using the principles of natural bypass, see Figure 3. The new layout includes a downdrift breakwater, streamlining of the entrance by a small extension of the existing main breakwater to the southwest and a shortening of the updrift groyne. It is expected that the contraction of the wave-driven currents around the harbour entrance will be enough to maintain an equilibrium depth in front of the harbour, which will be suitable for navigation. Strong, but well-defined, currents will be present in front of the entrance during storms. The large outer harbour basin makes this current pattern acceptable for navigation in rough weather. The present sedimentation problem related to waves from a south-westerly direction will be alleviated. The naturally bypassed sediment from north to south, will, with time, develop a bypass shoal and start to feed the downdrift beach. The new layout can be seen from Figure 5.

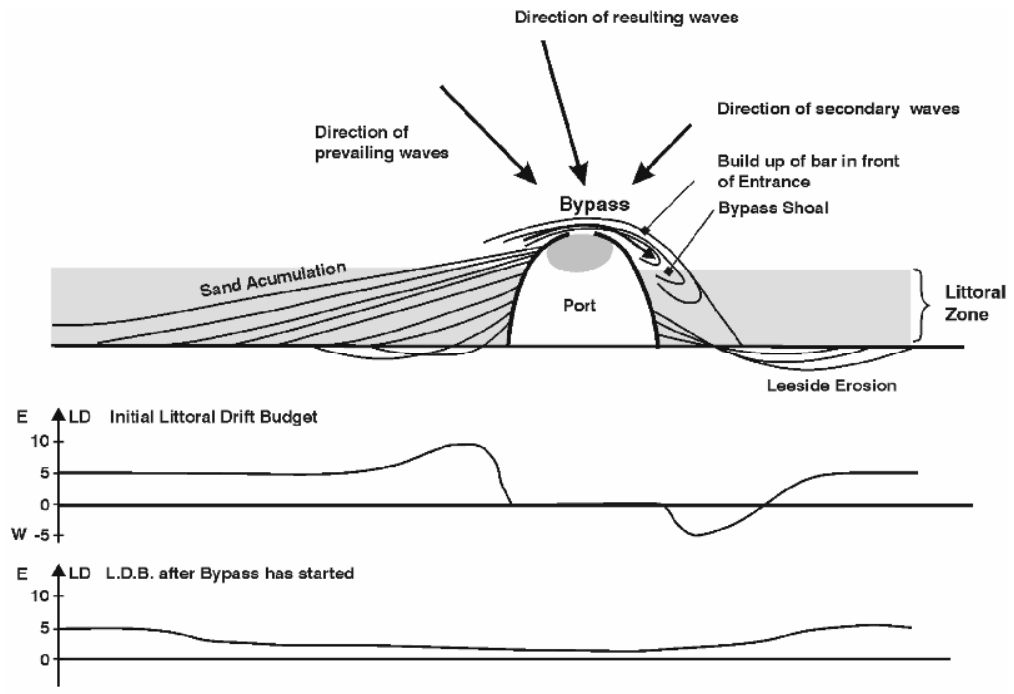

Figure 3: $\quad$ Sketch of bypass harbour, from Mangor (2004). 
The critical parameter for the new harbour layout is the equilibrium depth at its entrance. This equilibrium depth is reached when the sediment transport capacity in front of the harbour is similar to the updrift littoral transport. The equilibrium depth has been evaluated using morphological modelling, i.e. simulation of waves, currents, sediment transport and bed level changes, with continuous updating of the bed levels and the subsequent re-calculation of waves, currents and sediment transport. The use of a (2D) morphological area model paves the way for the possibility of following the bed development with time during storm conditions. This is a large step forward for the modelling procedure. Previously, coastal studies often relied on time series of sediment transport on a fixed bed.

The morphological modelling complex has been calibrated and validated against measured pre-storm and post-storm bathymetries of the harbour entrance for two storms from the northwest and southwest, respectively. The Danish Coastal Authority maintains a directional wave meter $3 \mathrm{~km}$ northwest of the site. These recordings have been used as boundary conditions for the morphological modelling complex. General surveys are available for each summer, but detailed surveys are carried out regularly, especially after a severe event has taken place around the harbour entrance. The pre-storm and post-storm bathymetries measured around the entrance, as well as the model bathymetry prior to the storm (lower left panel), are shown in Figure 4.

The lower right panel shows the modelled post-storm bathymetry. It can be seen that the sand shoal off the main breakwater was pushed to the south during the storm and that the model is able to reproduce this process. The calibration of the morphological modelling complex comprised the tuning of bed roughness and wave breaking parameters.

Figure 5 shows the result of a repetition of the simulation of the October 1997 storm with the new breakwater and redesigned existing structures. The left panel is the initial bathymetry, the right panel is the bathymetry after the storm. It appears that a water depth of about $3.5 \mathrm{~m}$ can be maintained in front of the entrance after the storm with the modified layout. Furthermore, no sedimentation seems to have taken place in the entrance area. 

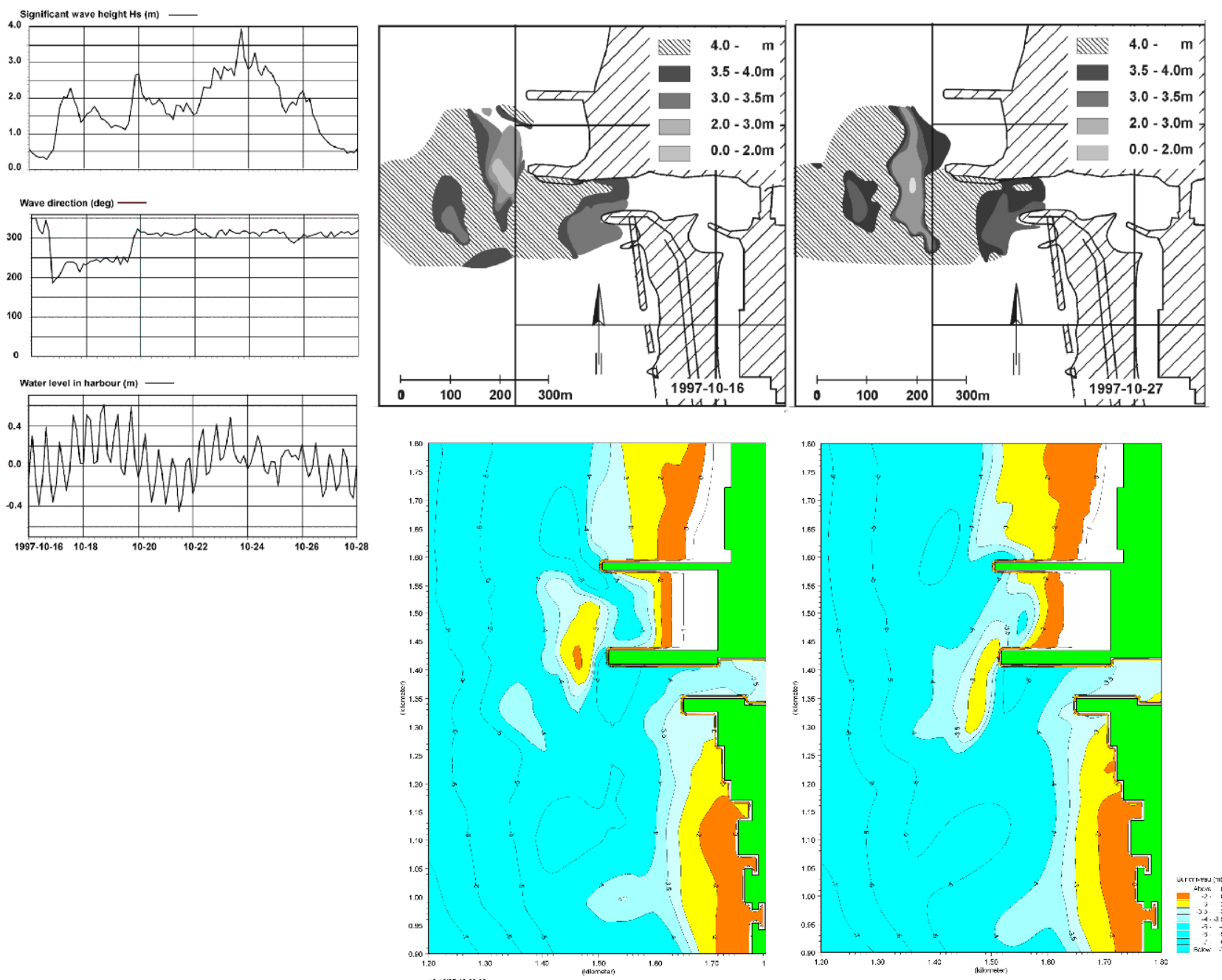

Figure 4: Boundary conditions, observed pre-storm and post-storm bathymetries, simulated prestorm and post-storm bathymetries, 16 and 27 October 1997.
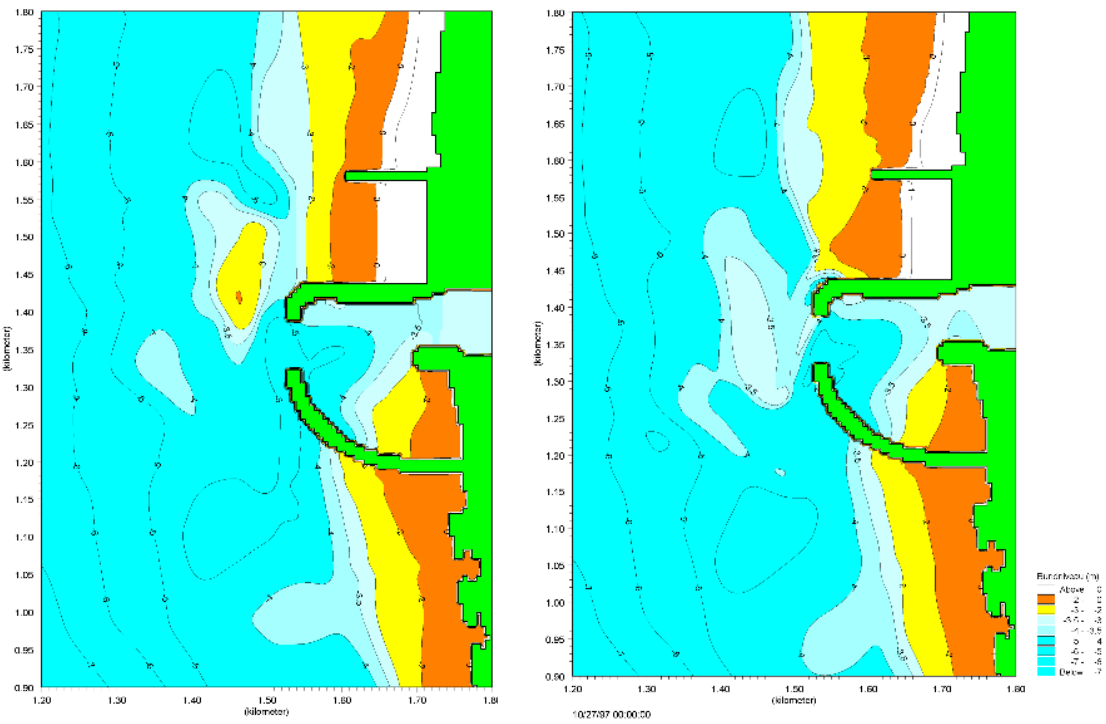

Figure 5: New layout. Morphological modelling of the October 1997 storm. 
The "equilibrium" depth in front of the harbour was investigated through six thirty-day morphological simulations with persistent wave conditions. The bathymetries after 30 days of constant wave conditions, $\mathrm{H}_{\mathrm{s}}=3.5 \mathrm{~m}$, from the northwest are shown in Figure 6 together with the initial bathymetry. The initial bathymetry included a deep area in front of the harbour, down to $-6 \mathrm{~m}$, i.e. just after dredging. The simulation results show that this deep area is migrating to the south and is filling in. After about 20 days of constant wave action, the water depth at the entrance stabilises at approx. $3.3 \mathrm{~m}$, see Figure 6 where the lower panel shows the bed level changes with time at two points, A and B, just off the existing main breakwater and at the entrance. It appears that large-scale bed forms migrate towards the south in the morphological model and that the "equilibrium bed level" at the entrance is dynamic, with a minimum depth of around $3.2 \mathrm{~m}$.
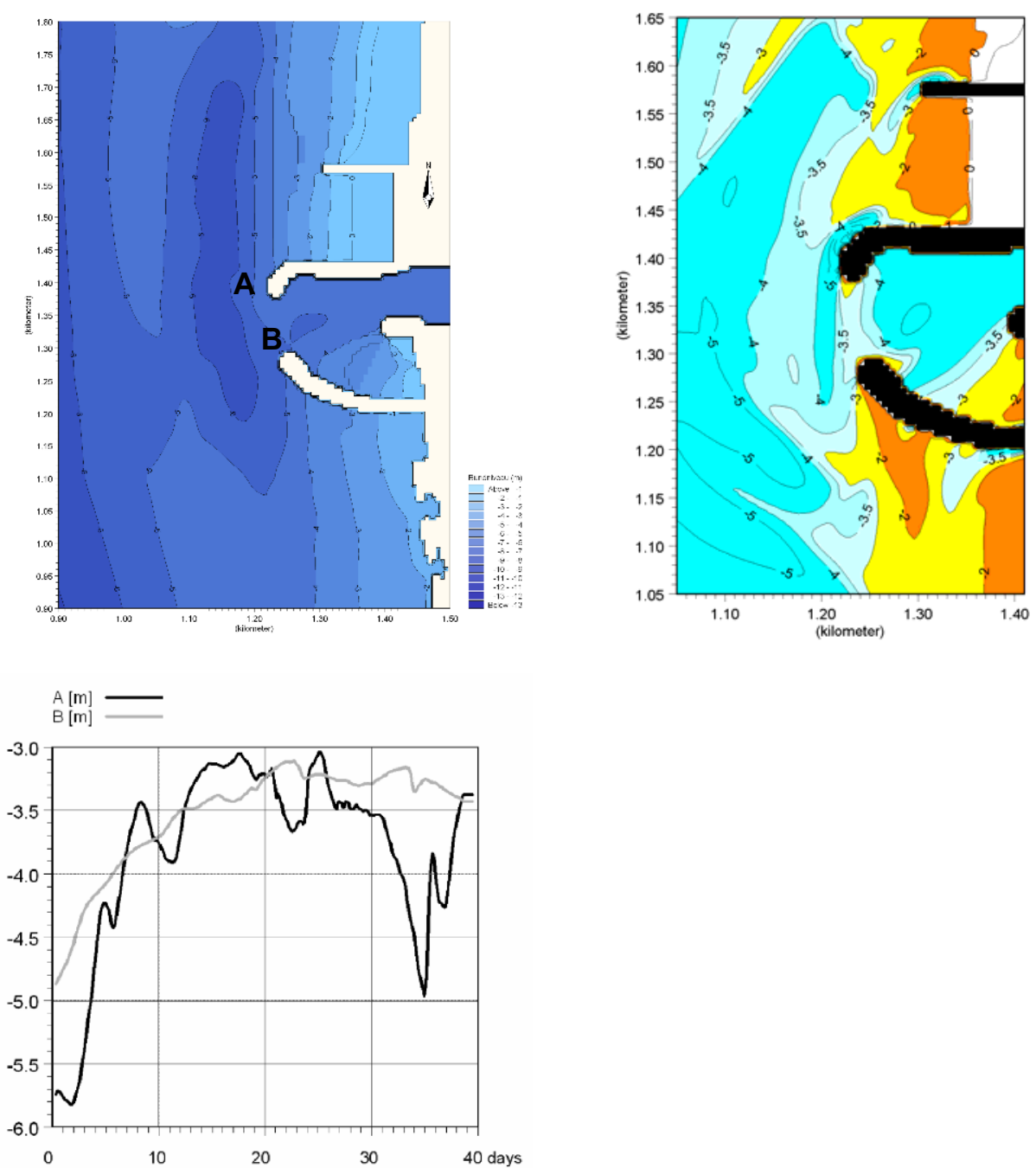

Figure 6: Modelled morphological evolution for constant waves, Hs $=3.5 \mathrm{~m}$ and $315^{\circ}$. Bathymetries after 0 days and 30 days. Time series of bed level in points $A$ and $B$.

The results seem to indicate that the $3 \mathrm{~m}$ depth contour never reaches the tip of the 
northern breakwater. A shoal develops immediately downdrift of the harbour, in the area where the contracted current expands after flowing across the entrance. This shoal keeps growing until the depth decreases to a level where the sediment transport capacity, due to wave breaking and wave-driven currents, corresponds to the amount which bypasses the harbour.

Development since implementation. The new breakwater was finished in the autumn of 2004. The first two winters indicate a reduction in dredging to one third of the amounts before the re-design which is enough to not have permanent dredging equipment in the harbour.

The morphological modelling complex proved to be a useful tool in supporting the understanding of the processes around the harbour and thereby the layout of the re-designed harbour.

Hanstholm harbour on the West Coast of Denmark is an example of a very successful harbour located near a headland on an exposed coastline, see Figure 1 for location map and layout. The harbour is a fishery and ferry port built in the 1960s at a critical location with about 0.4 million $\mathrm{m}^{3} /$ year net northward transport and a gross transport of around 1.5 million $\mathrm{m}^{3} /$ year, see Sørensen et al (1996).

The symmetrical and streamlined layout creates a smooth convergence of the flow past the harbour entrance and has in combination with vertical breakwaters resulted in acceptable sedimentation rates. However, the importance of the flow immediately off the entrance is discussed in what follows. The sedimentation is localized in the outer harbour immediately inside the entrance, and a natural depth in the entrance area is about $9 \mathrm{~m}$. The average yearly sedimentation in the harbour is $80,000 \mathrm{~m}^{3}$. The flow around Hanstholm harbour is mainly driven by meteorological forcing, variations in wind and pressure, and, to a smaller extent, by wave breaking. Tide is very limited in this area. An extension is planned on the western side of the existing harbour. The implications of the extension on the sedimentation in the harbour are discussed in the following. The present and the proposed harbour layouts are shown in Figure 7.

The harbour layout was originally optimised by the use of physical modelling techniques to obtain minimum sedimentation in the harbour. The design has been successful with a yearly maintenance dredging inside the outer harbour of 80,000 $\mathrm{m}^{3} / \mathrm{yr}$. Dredging outside the harbour is not required.

The wave statistics at $20 \mathrm{~m}$ water depth off Hanstholm Harbour are illustrated by the wave rose in Figure 7. The westerly and south-south-westerly directions are dominant and the significant wave height exceeds $4 \mathrm{~m}$ approx. $0.5 \%$ of the time and $5 \mathrm{~m}$ approx. $0.1 \%$ of the time. The wave periods are relatively short due to the fetch limitations of the North Sea. 


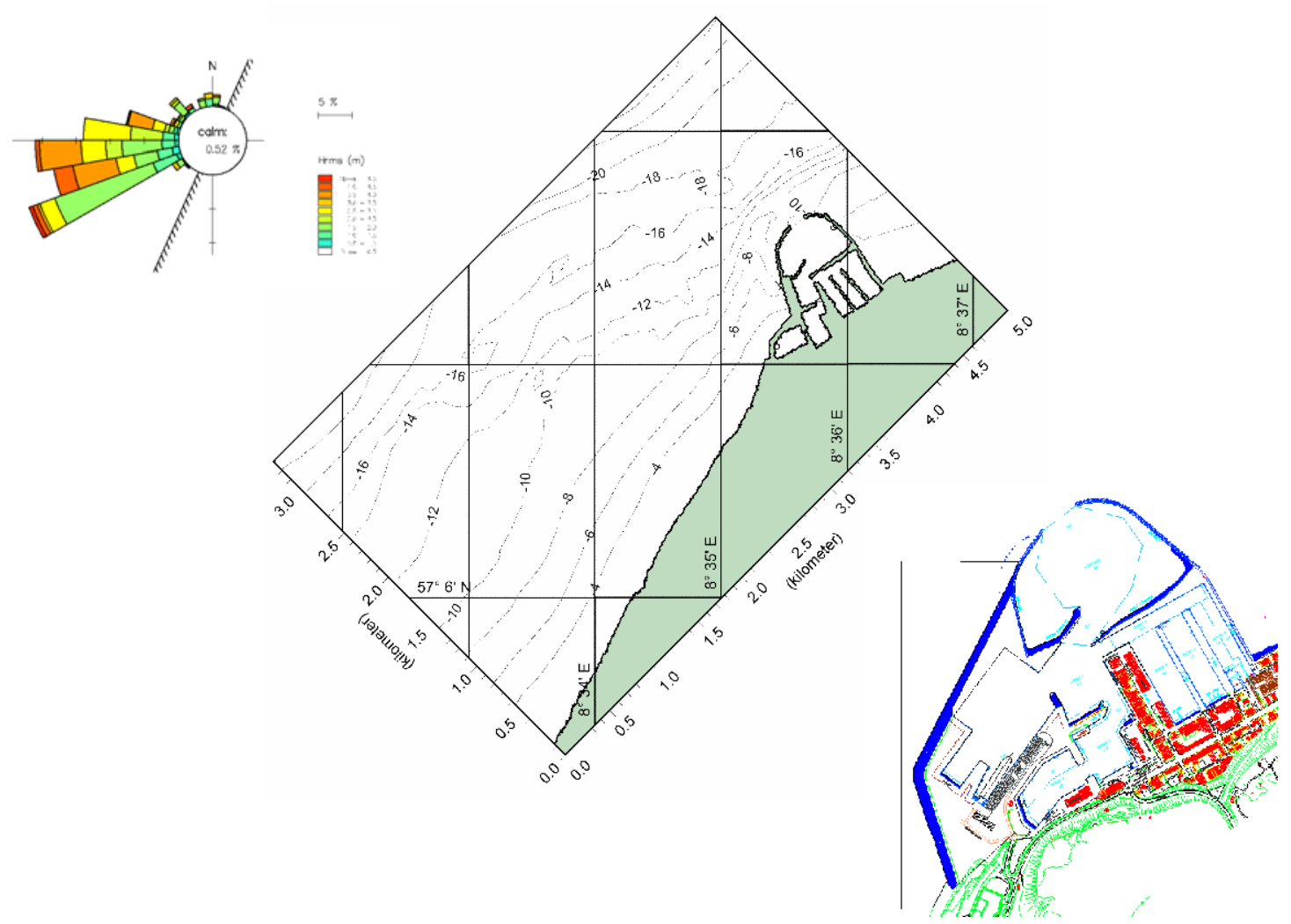

Figure 7: The existing layout (upper part) and the proposed new layout (lower part). Wave rose at $20 \mathrm{~m}$ water depth.

At the present stage of preliminary design and layout testing it has been chosen to focus on the understanding of the dominating processes around the harbour entrance and make comparisons for selected combinations of currents and waves. The important processes for sediment bypass and sedimentation are related to:

1) Flow pattern around the harbour and near the entrance area on a time scale of more than 20 minutes.

2) Large-scale eddies formed in the entrance area with a time scale of minutes.

The former type of process has be studied by the combination of numerical models of waves, depth integrated currents and sediment transport capacity. The later type of process requires a model resolution fine enough in space and time to capture the relevant eddies.

Large-scale processes, type 1. As the harbour is located on a headland where both ocean currents and the wave driven currents generated within the surf zone are important, several cases with different relevant wave/current combinations have been studied. The currents outside the surf zone are driven by a difference in water level between the two shore perpendicular boundaries of the model area. The difference is determined from the offshore current and the hydraulic roughness. In this way, the use of a regional flow model has been avoided. The resolution of the model set-up for the study of the Type 1 process is $10 \mathrm{~m}$. An 
example of the simulated waves, currents and sediment transport around the existing harbour is presented in Figure 8 together with currents and sediment transport capacity for the extended harbour. This example represents the combination of $\mathrm{Hs}=4.6 \mathrm{~m}, \mathrm{Tp}=9.3 \mathrm{~s}, \mathrm{MWD}=265^{\circ} \mathrm{N}$ and an offshore current corresponding to $\mathrm{V}=0.85 \mathrm{~m} / \mathrm{s}$.

It is noticed how the new, more streamlined up-drift breakwater guides the currents past the harbour entrance with higher currents close to the entrance compared with that of the existing layout. The sediment transport capacity reflects the flow field. It appears that the transport capacity decreases along the proposed long main breakwater leading to deposition. The details of the flow and sediment transport patterns off the entrance to the harbour are shown in Figure 9. With the new layout it is clearly seen that the currents increase close to the entrance as compared to the existing layout. The increase in transport capacity immediately outside the entrance leads to an increase in the transport capacity both across the entrance and into the harbour.

Eddies in the entrance, type 2. The eddies in the entrance have initially been studied by the depth integrated hydrodynamic model used above but with a resolution of $1 \mathrm{~m}$ compared to preciously $10 \mathrm{~m}$ This approach is deemed sufficiently accurate to be able to compare the results for different layouts. An example of a snapshot of the flow field in the entrance with the extension in place and the variation in the current speed and direction at the down-drift breakwater (P4) are presented with and without the harbour extension in Figure 10.

The impact of the increased eddy intensity in the entrance area have been visualised by calculation of the path ways of sand particles released in the middle of the water column upstream of the entrance. The resulting deposition pattern for the two cases is shown in Figure 11. It appears that the present breakwater configuration does not entail eddy-related sedimentation. In the case with the harbour extension in place eddies in the entrance are clearly actively feeding the outer harbour with sediment, which will remain within the harbour due to the low wave/current exposure. (Sand deposited outside of the breakwaters will resuspend due to the high exposure to current and waves and will consequently be transported downstream. This mechanism is not included in the simple path way calculation). Results for refined flow modelling of the processes in the entrance will be shown at the presentation.

The preliminary investigations have shown that the Hanstholm breakwaters are constructed in a way that slightly deflects the current seaward just upstream of the entrance area. The bypass of sediment thus takes place a certain distance from the entrance area. The deflection of the current reduces the eddy intensity in the entrance area and thus the sedimentation of the outer harbour. More detailed investigations shall confirm these findings. 

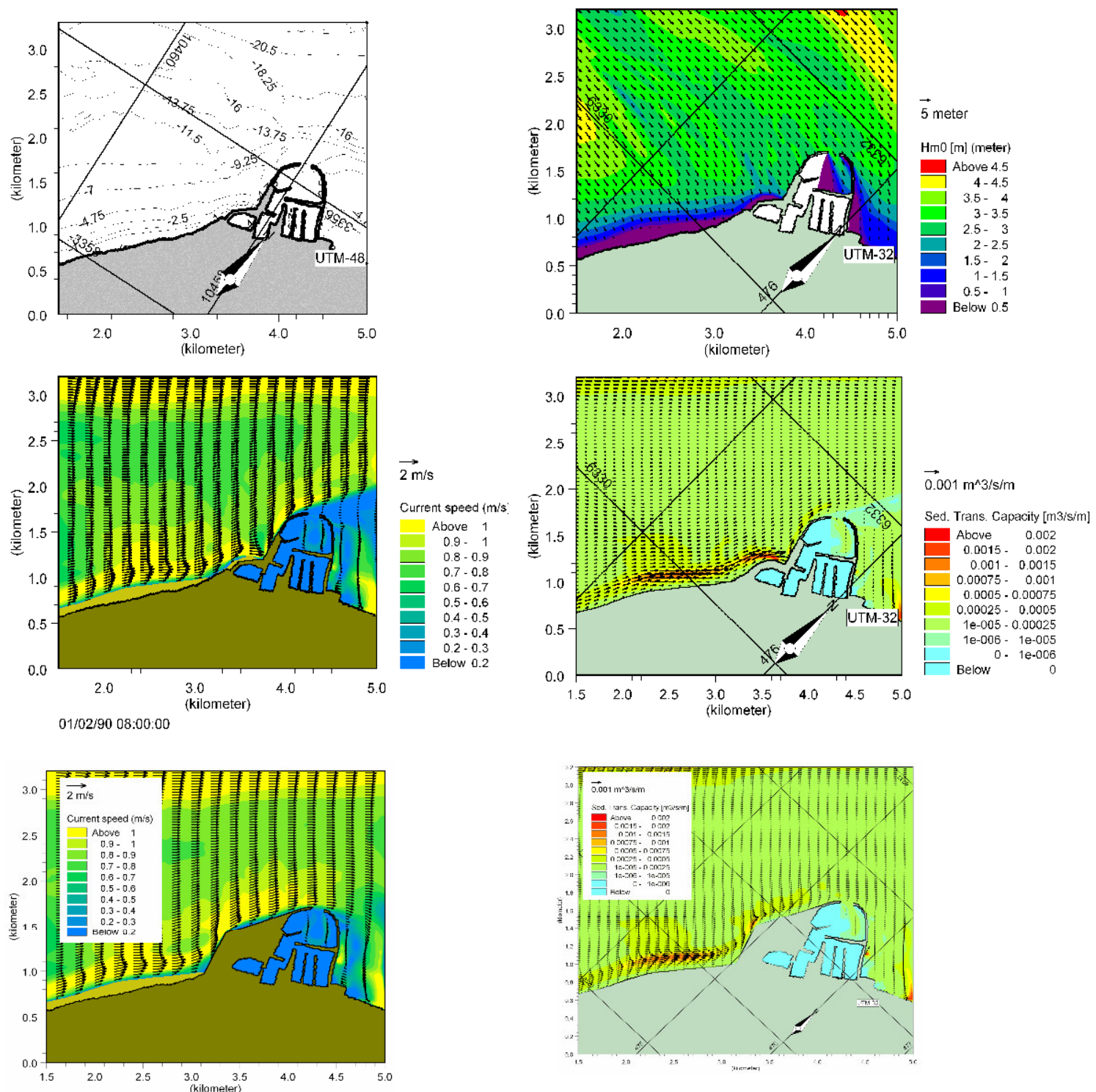

Figure 8: Bathymetry, waves, currents and sediment transport, existing layout. Currents and sediment transport for extended harbour.
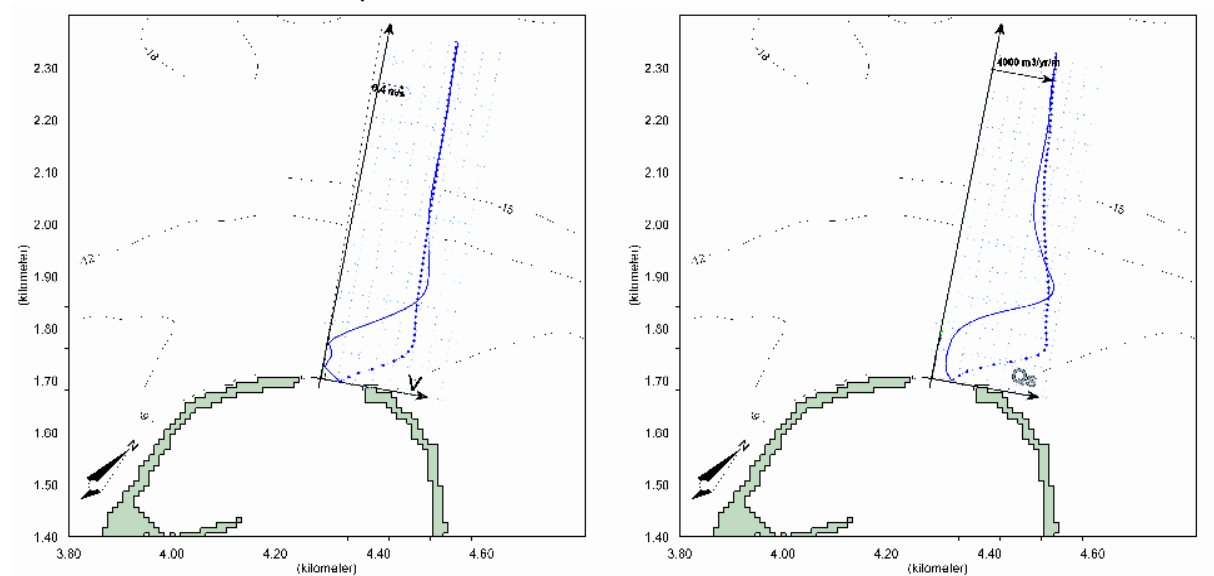

Figure 9: Details of the depth integrated currents (left) and sediment transport capacity (right) 
IXèmes Journées Nationales Génie Civil - Génie Côtier, 12-14 septembre 2006, Brest

outside the entrance for present (lines) and proposed (dots) layout.
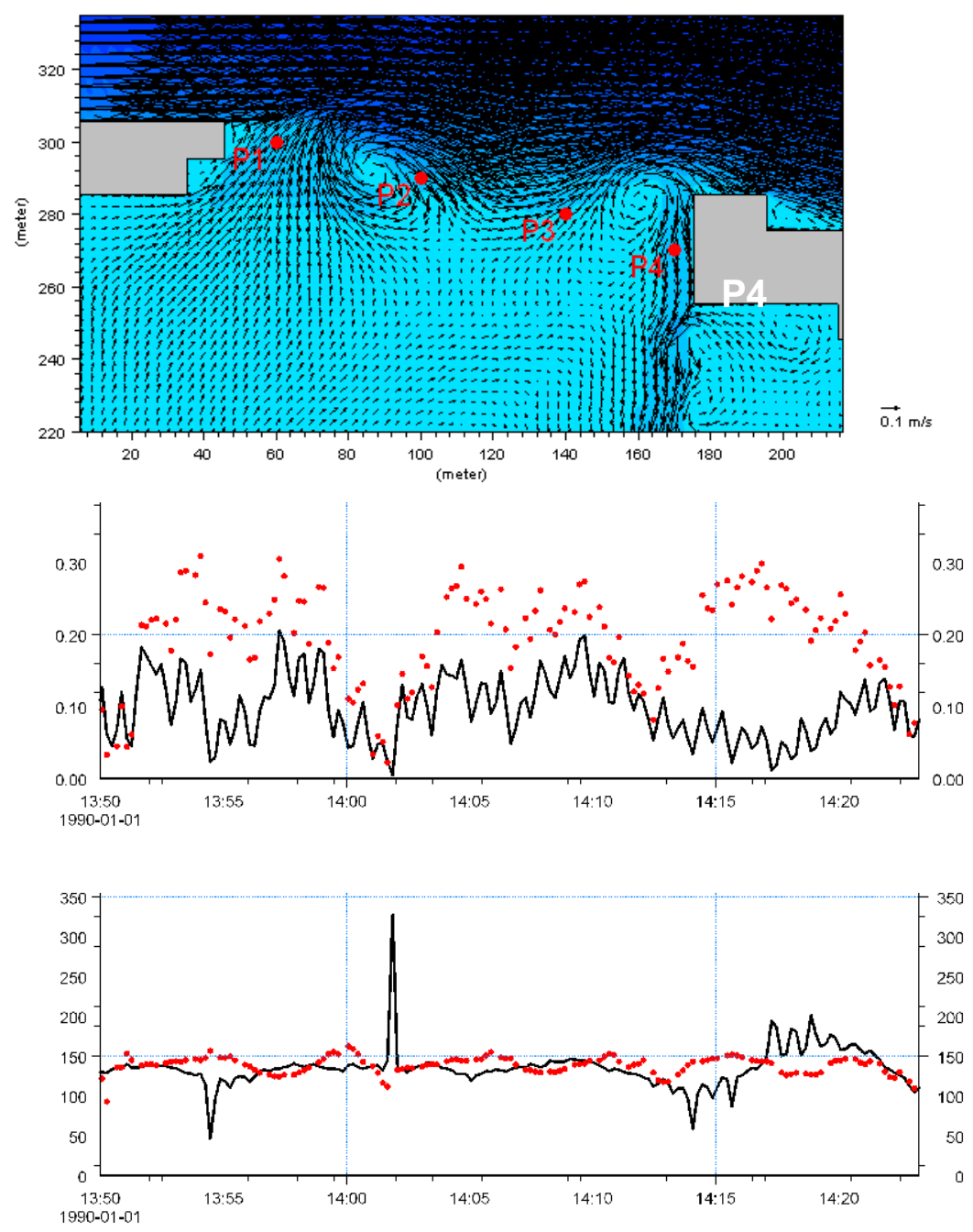

Figure 10: Snapshot of depth-integrated flow field in the entrance with breakwater extension using the $1 \mathrm{~m}$ model complex. Time-series of speed and direction of current at P4. Line: existing conditions. Spots: with new layout.
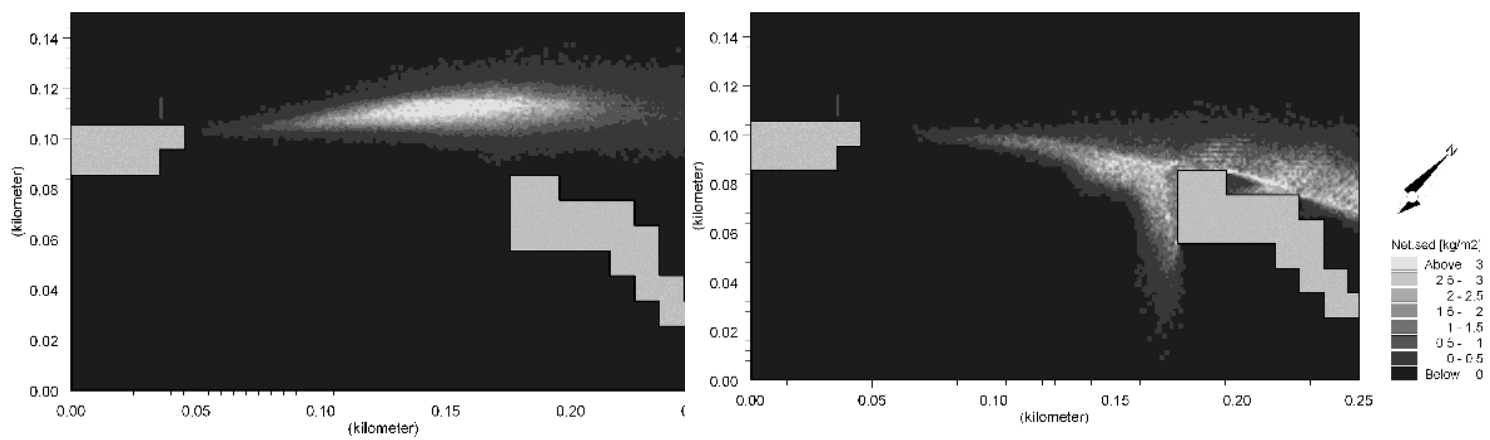

Figure 11: Sedimentation pattern before (left) and after (right) breakwater extension. 


\section{Artificial Beaches}

Two cases of artificial beaches where the design has been heavily supported by numerical modelling will be briefly presented. Artificial beaches are designed to minimise the loss of sand, to maintain a good beach quality by natural means and to secure safe swimming conditions. The fulfilment of these criteria requires the analysis of basis processes and parameters such as equilibrium orientations and distribution of littoral drift at the location prior to the development of schemes, and subsequently testing and optimisation of layouts.

Amager beach is located out to the Sound in Copenhagen, Denmark. The problem at this site is that the existing beach is of a poor quality (muddy shoreface) due to the lack of wave exposure. The site is only moderately exposed and the existing beach is further protected due to a very shallow shoreface, see Figure 12. A new beach park was recently built at this location. The project includes $2 \mathrm{~km}$ of new beaches and is located less than $10 \mathrm{~km}$ from the Copenhagen city centre.

The main concept for the new beach park has been to move the beaches seaward beyond the shallow shore-face and thereby providing the highest possible wave exposure, which, however, is still moderate. The new beaches have been constructed on an island and a new lagoon (deepened) has been excavated between the island and the old shoreline. As the beach park is located near the gorge section of the Sound between Denmark and Sweden, there is always a good gradient on the water surface in the area of the beach park. This situation has been utilised to generate good flushing in the lagoon by making two openings, one at the northern and one at the southern end.

The wave climate at the site is characterised by having two main directions, i.e. NE and SE, see Figure 12, which is due to the shelter provided by the island located just opposite of the site. This situation has been utilised to create two sections of beaches separated by a headland, one facing towards the NE and one facing towards the SE. The headland provides shelter at the NE facing beach for waves from the SE and shelter at the SE facing beach for waves from the NE, respectively, see Figure 13. The layout can be seen in Figures 13 and 14. 


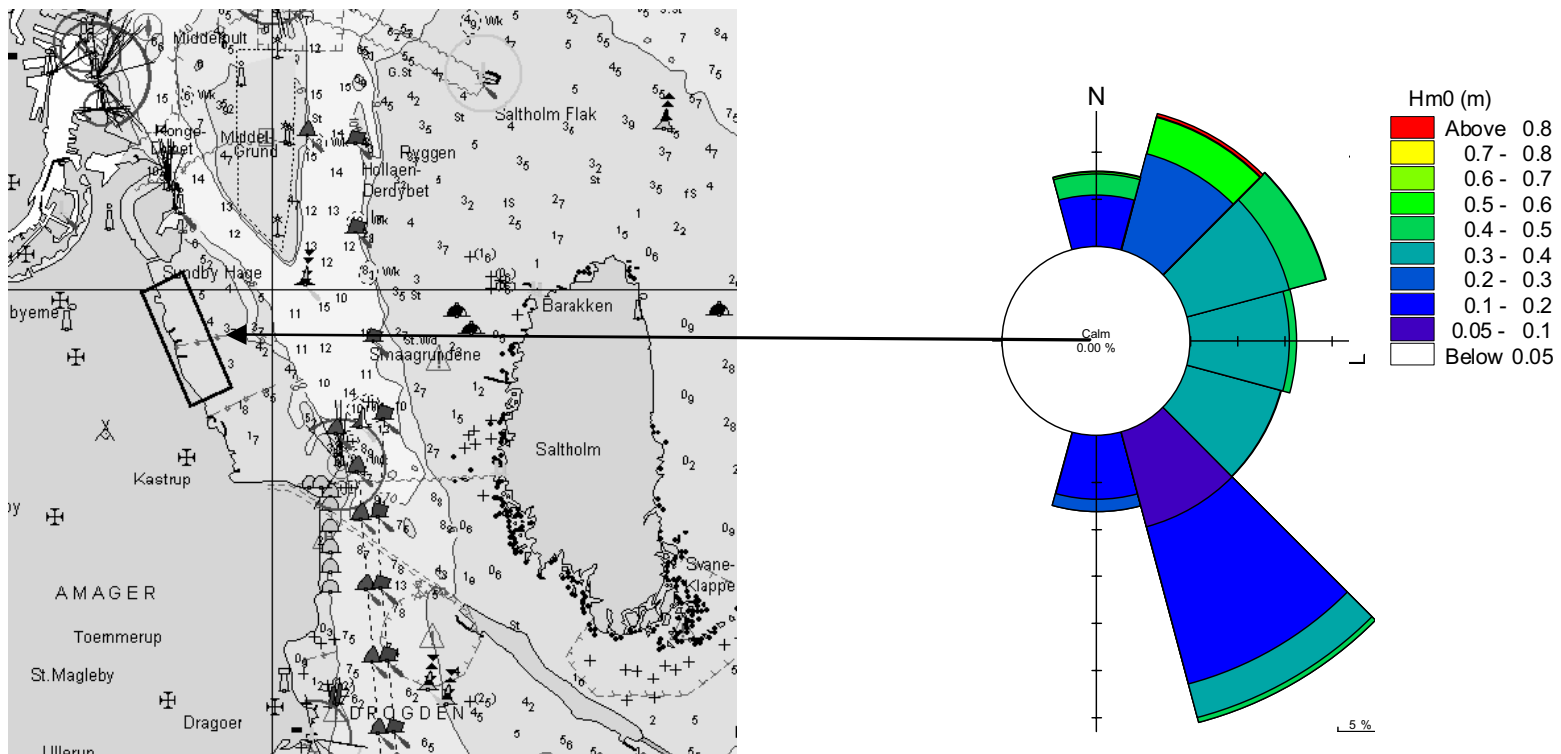

Figure 12: Amager Beach, Copenhagen, Denmark. Moderately exposed site with a protected beach due to a shallow shoreface.

The exact equilibrium shapes of the two beaches have been established based on modelling of a large number of wave conditions. The equilibrium orientations, i.e. orientations of zero net transport were calculated in a number of points along the coastlines. Finally, the shapes of the beaches were fitted to the series of equilibrium orientations. The length of the central headland is one of the parameters which were optimised through this process. The flushing of the lagoon was quantified by a depth-integrated hydrodynamic model. The average flushing time is about 24 hours, which will secure a good water quality. An aerial photo of the new beach park just after finalisation of the civil works is presented in Figure 14.
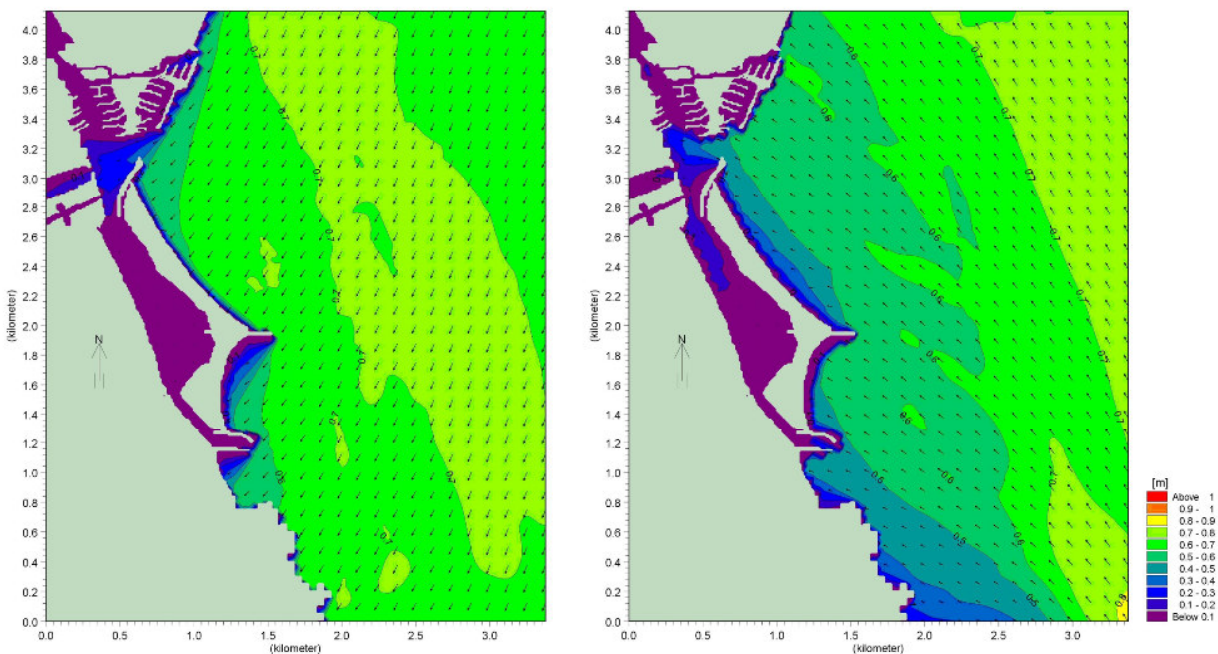

Figure 13: Modelling of wave patterns from the two main directions NE and SE. 


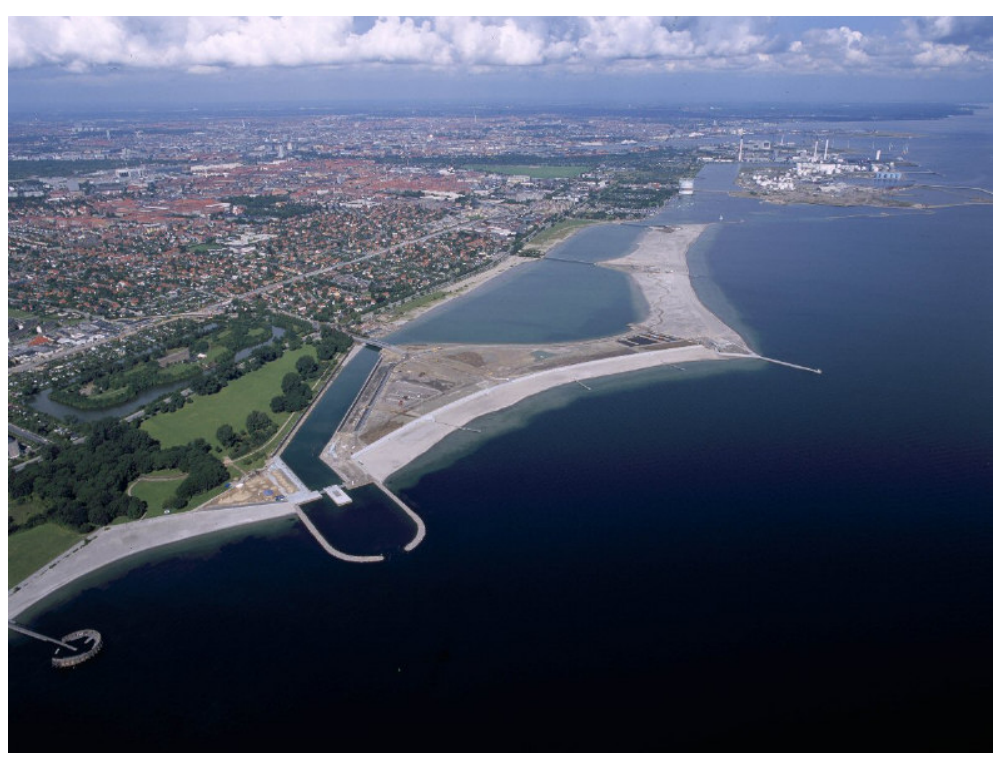

Figure 14: Aerial photo of Amager Beach Park, which consists of the following main elements: Island with terminal structures north and south and a separating headland between the northern and southern beaches and a lagoon.

New beach at La Nourriguel. The south coast of Brittany consists of many small pocket beaches confined between rocky headlands. This is also the case at Nourriguel (LarmorPlage). To the west of the entrance to the estuary at Lorient natural attractive beaches exist, see figure 15 for an overview.

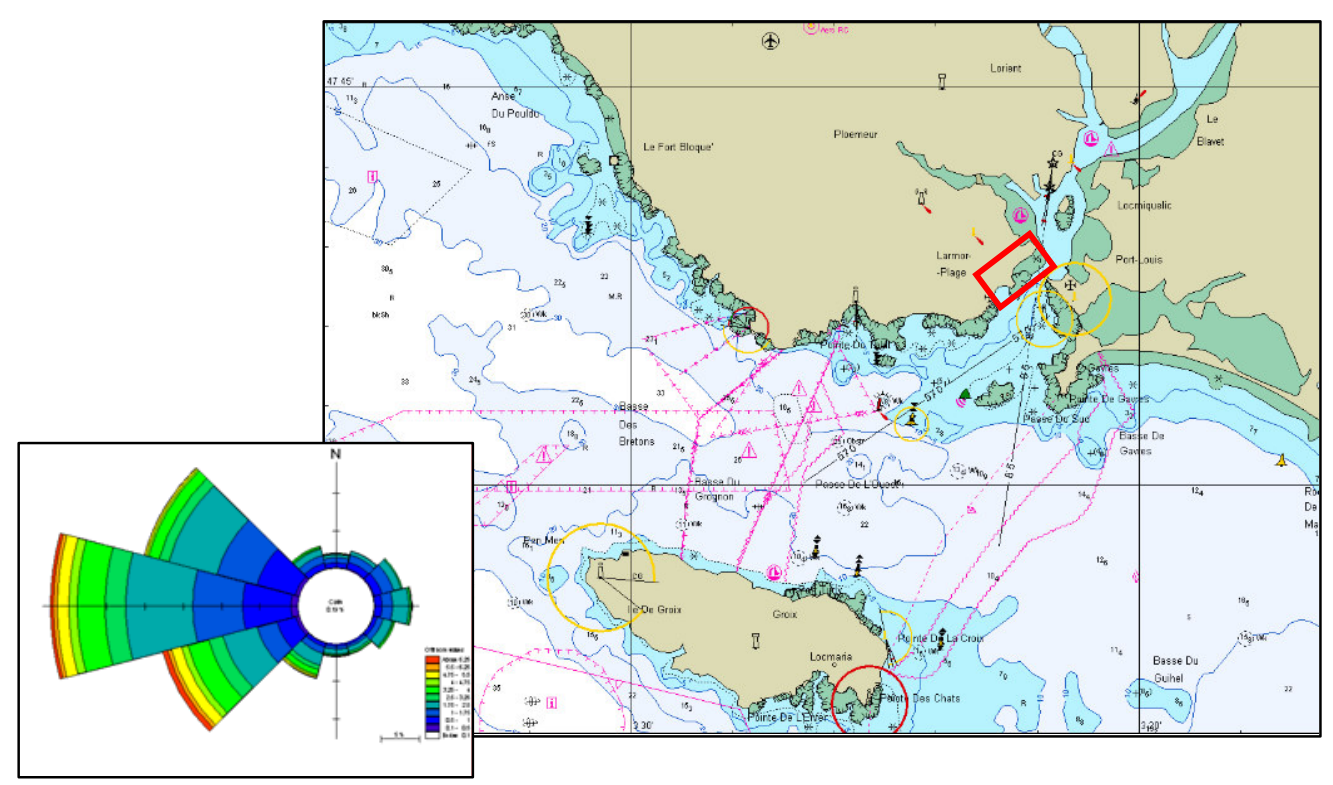

Figure 15: Overview of the estuary at Lorient, La Nourriguel and offshore wave statistics.

The sea front at La Nourriguel was developed with residential buildings during the first two decades of the $20^{\text {th }}$ century. Already at that time the coastline was slowly retreating due to the infrequent extreme waves, which penetrate the entrance. A vertical wall was installed in the fifties to protect the buildings. The erosion process in front of the wall has however continued and a new protection scheme is needed. Initially re-enforcement of the 
wall was suggested. However, detailed numerical modelling confirmed that the actual potential erosion is relatively small and that the equilibrium shape of a sandy beach could be established by construction of a groyne or headland at the northern end of the new beach. The new beach has been re-aligned compared to the existing beach to face the dominant waves. Thereby the loss of sand from the new beach will be very limited. Figure 16 shows an aerial photo of the existing coast, with the two natural, stable sandy pocket beaches to the left and to the right an artistic impression of the new artificial beach supported by a groyne in the far north end. It appears that the equilibrium shape of the new beach is turned slightly anti-clockwise compared to the natural pocket beaches. This turning is due to the fact that the waves refract slightly more before they reach the new beach compared to the natural beaches further to the south west. The sandy beach will absorb the extreme wave energy before the waves reach the wall in the rare cases of events of extreme waves and high water. In the daily situation the beach will be a new asset for the area.

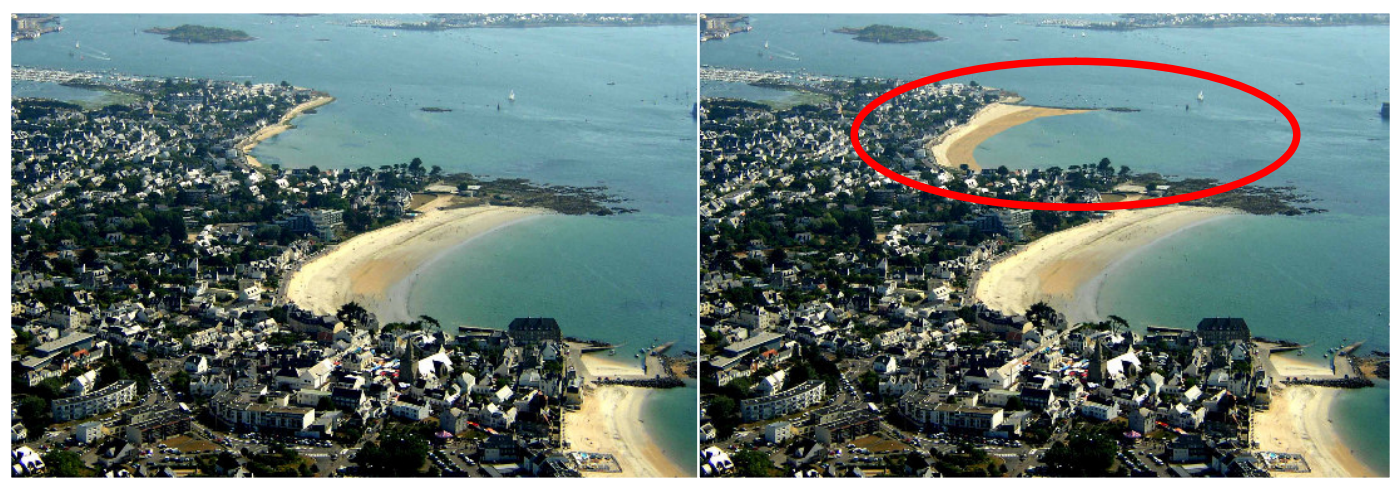

Figure 16: Left: aerial photo of existing pocket beaches. Right: Artistic impression of the new artificial beach

\section{Conclusions}

The paper shows examples of the use of advanced hydraulic modelling tools for the design of coastal structures and development schemes. However, it is also demonstrated that the modelling exercises will only be successful if the scheme concepts have been developed through understanding and utilisation of the site specific hydraulic and coastal mechanisms, which are characteristic for the project site.

The optimal use of numerical models can therefore briefly be characterised as follows:

- Perform basic hydraulic and coastal studies utilising existing data and regional numerical models.

- Develop concepts for development schemes by utilising the basic information on coastal processes and the concept of "work with nature".

- Utilise detailed numerical models to optimise the hydraulic and coastal performance of the schemes including optimisation through minimisation of negative impacts. 


\section{References}

Abbott M.B. 1979. Computational hydraulics, elements of the theory of free surface flows. Pitman, London.

Battjes, J.A. and Janssen J.P.F.M. 1978. Energy loss and Set-up due to breaking of random Waves. Procs. of the $16^{\text {th }}$ Int. Conf. On Coastal engineering, ASCE, 569-587.

Christensen, ED., Bredmose, H. and Hansen EA. (2005). Extreme wave forces and wave run-up on offshore windturbine foundations. Proceedings of Copenhagen Offshore Wind 2005, Copenhagen October 2005.

Deigaard, R. 1993. A note on the 3-dimensional shear stress distribution in a surf zone". Coastal Engineering, 20, 157-171.

Deigaard, R., Fredsøe, J. and Brøker Hedegaard, I. 1986. Suspended sediment in the surf zone. J. Waterway, Port, Coastal and Ocean Engineering, 112 (1), ASCE, 115-128.

Deigaard, R.; Fredsøe, J., and Brøker, I. (1986). Mathematical model for Littoral Drift. Journal of Waterway, Port, Coastal and Ocean Eng., ASCE, Vol. 112, No. 3, pp. 351-369.

Elfrink, B., Brøker, I. and Deigaard, R. 2000. Beach Profile Evolution due to Oblique Wave Attack. Procs. of the $27^{\text {th }}$ Int. Conf. on Coastal Eng., ASCE, 3021-3034.

Fredsøe J. 1984. The turbulent boundary layer in combined wave-current motion. Journal of Hydr. Eng., 110(8), ASCE, 1103-1120.

Fredsøe J, Deigaard R. 1992. Mechanics of coastal sediment transport.World Scientific. Advanced series on ocean engineering

Holthuijsen, L.H., Booij, N. and Herbers, T.H.C. 1989. A prediction model for stationary, short-crested waves in shallow water with ambient currents. Coastal Engineering, 13, 23-54.

Johnson, H.K.; Brøker, I.; and Zyserman, J.A. 1994. Identification of some Relevant Processes in Coastal Morphological Modelling. Proceedings of the 24th International Conference on Coastal Engineering, ASCE, 2871-2885.

Johnson, H.K. and Zyserman, J.A. 2002. Controlling spatial oscillations in bed level update schemes. Coastal Engineering, 46, 109-126.

Kirby, J.T. 1986. Rational approximations in the parabolic equation method for water waves. Coastal Engineering, 10, 355-378.

Mangor, K. 2004. Shoreline Management Guidelines, DHI Water \& Environment, 232p.

Mayer, S., Garapon, A. and Sørensen, L.S., 1998. A fractional step method for unsteady free-surface flow with application to non-linear wave dynamics. Intl. Journal for Numerical Methods in Fluids, Vol. 28, No. 2, pp. 293-315.

Sørensen, T.; Fredsøe J.; Roed Jakobsen, P.(1996) History of coastal engineering in Denmark. History and heritage of coastal engineering, ASCE. 